DE

M E D I C I N A

T R O P I C A L

$\mathrm{DE}$

SÃO PAULO

JOURNAL OF THE SÃO PAULO INSTITUTE OF TROPICAL MEDICINE

(1) Universidade de São Paulo, Faculdade de Odontologia de Ribeirão Preto, Departamento de Morfologia, Fisiologia e Patologia Básica, Ribeirão Preto, São Paulo, Brazil

(2) Universidade de São Paulo, Faculdade de Odontologia de Ribeirão Preto, Departamento de Estomatologia, Saúde Coletiva e Odontologia Legal, Ribeirão Preto, São Paulo, Brazil

(3) Universidade de São Paulo, Faculdade de Medicina de Ribeirão Preto, Departamento de Medicina Interna, Ribeirão Preto, São Paulo, Brazil

Correspondence to: Alan Grupioni Lourenço

Universidade de São Paulo, Faculdade de Odontologia de Ribeirão Preto, Departamento de Morfologia, Fisiologia e Patologia Básica, Via do Café s/n, CEP 14040-900, Ribeirão Preto, SP, Brazil Tel: +551633154010 .

E-mail: alancravinhos@yahoo.com.br

Received: 5 July 2016

Accepted: 31 March 2017

\section{Oral Candida spp carriage and periodontal diseases in HIV- infected patients in Ribeirão Preto, Brazil}

\author{
Alan Grupioni Lourenço', Ana Elisa Rodrigues Alves Ribeiro', Cristiano \\ Nakao', Ana Carolina Fragoso Motta², Luana Grupioni Lourenço Antonio³, \\ Alcyone Artioli Machado ${ }^{3}$, Marilena Chinali Komesu' ${ }^{1}$
}

\section{ABSTRACT}

The majority of HIV-infected patients develop Candida spp-associated clinical oral lesions. Studies have shown that asymptomatic oral colonization of Candida spp may lead to oral lesions or become a source of disseminated infections. The aim of this study was to verify the effects of periodontal conditions on Candida spp prevalence and Candida spp carriage in the oral cavity of HIV-infected patients compared to non-infected patients. Twenty-five patients not infected with HIV and $48 \mathrm{HIV}$-infected patients were classified according to periodontal conditions as being periodontal healthy or with periodontal disease. Candida spp carriage and classification were performed in oral rinse samples. Viral load and $\mathrm{CD} 4^{+} \mathrm{T}$ lymphocyte $(\mathrm{CD} 4+\mathrm{L})$ counts were performed in blood samples from HIV-infected patients. No differences in Candida spp prevalence related to HIV status or periodontal condition were detected. However, Candida spp carriage was increased in periodontally affected HIVinfected patients when compared to periodontally healthy HIV-infected patients $(p=0.04)$. Periodontally healthy HIV-infected patients presented Candida spp carriage in similar levels as healthy or periodontally affected non-HIV-infected patients. Candida spp carriage was correlated with CD4+L counting in HIV-infected patients. We concluded that periodontal disease is associated with increased Candida spp carriage in HIV-infected patients and may be a predisposing factor to clinical manifestations of candidiasis.

KEYWORDS: HIV infection. Oral Candida carriage. Periodontal disease. Candida spp.

\section{INTRODUCTION}

In the last few decades, an increase in the prevalence of fungal oral infections was observed and they seem to be related to the growing antibiotic use and the immunosuppressive condition, especially in AIDS patients ${ }^{1}$. Most of the infections are related to Candida spp, which is generally a commensal in the oral cavity, but in immunologically-compromised patients it can assume pathogenic characteristics ${ }^{2}$. Some studies showed that candidiasis comes from commensal strains and that asymptomatic oral colonization can lead to oral lesions or become a source of disseminated infections ${ }^{3-5}$.

C. albicans is the most common species isolated in oral candidiasis ${ }^{6}$; however, other species, such as C. tropicalis, C. glabrata, C. parapsilosis, C. stellatoidea, C. guilliermondii, and C. krusei were also observed ${ }^{7}$.

In healthy individuals, the prevalence of Candida spp in the oral cavity is $40-60 \%{ }^{8}$ while in HIV-infected patients, the prevalence increases to $62-93 \% 9,10$. Oral candidiasis is the most common lesion associated with HIV infection. It is 
considered one of the first clinical signs of HIV-related immunosuppression and it is highly predictable of the disease evolution ${ }^{11}$. Studies have shown that the prevalence of oral candidiasis varies between $20 \%$ and $70 \%$ in HIVinfected patients ${ }^{6,11}$, and although a decline in its prevalence has been observed after the antiretroviral therapy (ART) era $^{12}$, it is estimated that $90 \%$ of HIV-infected patients will develop oral candidiasis during the evolution of HIV infection ${ }^{13}$, emphasizing the importance of studies on this topic. Among the factors that predispose to oral candidiasis are smoking ${ }^{14}$, age ${ }^{3,15}$ and oral hygiene ${ }^{16}$. According to many studies, the presence of yeasts in the biofilm, mainly C. albicans, contribute not only to oral candidiasis, but to dental caries ${ }^{16,17}$ and periodontal disease ${ }^{18-20}$.

Studies on the correlation between Candida spp and the etiology and aggravation of periodontal diseases are important, but it is also essential to verify the effects of periodontal conditions on Candida spp carriage, either due to the possible correlation with the development of oral lesions or systemic disseminations ${ }^{3-5}$. Thus, due to the importance and prevalence of Candida spp associated with oral diseases in HIV-infected patients, the aim of this study was to identify different species of Candida in oral rinses from patients with and without periodontal disease in two population groups, with and without HIV infection. Furthermore, to quantify the number of Candida ssp colonies in the oral rinses between not infected and HIV-infected patients with and without periodontal disease.

\section{MATERIALS AND METHODS}

The study protocol was approved by the Ethics Committee of the Clinical Hospital of the School of Medicine of Ribeirão Preto, University of São Paulo, Ribeirão Preto (protocol No 3621/2011). The procedures were performed in accordance with the ethical standards on human experimentation and the Helsinki Declaration of 1975 and 1983 revision. Prior to selection, oral and written explanations about the research protocol were given to eligible participants. All patients provided a written informed consent before their participation in this study.

Twenty-five patients not infected with HIV and 48 HIVinfected patients were selected from the Clinical Hospital of the School of Medicine of Ribeirão Preto, University of São Paulo. Patients were over 18 years old, had more than 19 teeth, and had not received any periodontal treatment, antibiotic therapy, anti-inflammatory or antifungal therapy in the three months before the study participation.

All patients had no clinical signs of candidiasis and no history of complete or partial removable prosthesis use with palatal coverage. Participants with other oral lesions associated with HIV were not excluded from the study. Only patients who met the following criteria were selected: no clinical sign of periodontal disease, no probing depth greater than $4 \mathrm{~mm}$, no loss of attachment and less than $20 \%$ of sites with bleeding. Patients who presented more than $20 \%$ of sites with bleeding and/ or at least 4 sites with loss of clinical attachment and more than $3 \mathrm{~mm}$ and/or 4 sites with probing depths than $4 \mathrm{~mm}$ were also included.

HIV-infected patients presented HIV seropositivity confirmed by ELISA and Western Blot tests, as well as by a recent viral load and CD-4+ $4^{+}$lymphocyte $(\mathrm{CD} 4+\mathrm{L})$ count exams (at least three months before the beginning of the study).

\section{Patients' Clinical Evaluation}

Patients underwent examination and collection of an oral rinse sample. The periodontal exam was performed after the collection of the oral rinse sample, so bleeding could not possibly interfere with the quality of collected samples. For the periodontal exam, we used a millimeter periodontal probe and all teeth (except third molars) were probed at six sites: mesiobuccal, buccal, distobuccal, mesiolingual, lingual and distolingual. In each site, we performed three different measures: deep probing, loss of attachment and bleeding.

Related to the periodontal condition, patients were classified into periodontally healthy or with periodontal disease. The periodontally healthy were patients who had no clinical sign of periodontal disease, no probing depth greater than $4 \mathrm{~mm}$, no loss of attachment and less than $20 \%$ of sites with bleeding. The patients who were periodontally affected presented more than $20 \%$ of sites with bleeding and/ or at least 4 sites with loss of clinical attachment and more than $3 \mathrm{~mm}$ and/ or 4 sites with probing depths than $4 \mathrm{~mm}^{21}$.

\section{Biological Sample Collection}

\section{Oral Rinse Sample}

One day before collection, sterilized bottles with $10 \mathrm{ml}$ of PBS were prepared in autoclaves $(\mathrm{pH} 7.3,0.1 \mathrm{M})$ and conditioned at $4{ }^{\circ} \mathrm{C}$ until use. Before oral rinse collection, the subjects were instructed not to eat, drink, smoke or brush their teeth for one hour prior to sample collection to minimize the risk of contamination. Participants were instructed to rinse with $10 \mathrm{ml}$ of PBS for 60 seconds and spit inside a universal collector that was immediately centrifuged (2,000 g per 10 minutes). After centrifugation, supernatant was discarded and solid residue was diluted in $1 \mathrm{ml}$ of PBS. In the obtained solution, Candida spp was 
counted and identified. The count and identification of Candida spp were performed in the oral PBS rinse sample by the Samaranayke's technique, described in $1986^{22}$.

\section{Blood Collection}

For blood exams, $10 \mathrm{~mL}$ of blood were collected in vacuteiner tubes with ethylenediamine tetra-acetic acid (EDTA). Plasma was obtained by centrifugation of total blood ( $800 \mathrm{x}$ g per $10 \mathrm{~min}$.), divided in tubes and stored at $-80^{\circ} \mathrm{C}$ in a maximum period of six months, until its use.

\section{Laboratorial Analysis}

\section{Viral load and $C D 4+L$ count}

The HIV-Monitor kit (Roche Diagnostic Systems, Branchburg, NJ, USA) was used to quantify the HIV RNA (viral load) in -blood plasma. The RNA was extracted from the samples using a modified silica protocol (QIAmp RNA viral kit; Qiagen, Chatsworth, CA, USA), and polymerase chain reaction was performed using the HIV-Monitor kit (Roche Diagnostic Systems, Branchburg, NJ, USA). The $\mathrm{CD} 4+\mathrm{L}$ counts in the blood plasma were determined by flow cytometry (FACS), which was performed within three months after sample collection.

\section{Candida spp quantification}

The oral rinse samples were diluted in PBS to obtain three different concentrations: pure sample, 10x PBSdiluted sample and 100x PBS-diluted sample. One hundred microliters of each concentration was plated in duplicate on petri dishes with Agar Sabouraud-Dextrose and chloramphenicol and incubated at $37^{\circ} \mathrm{C}$ for 48 hours. The colony forming units per milliliter (CFU/ $\mathrm{ml}$ ) was obtained by the mean between duplicates of positive culture. Depending on the number of $\mathrm{CFU} / \mathrm{mL}$, counts were categorized into 0 (none), 1 (isolated, $<10 \mathrm{CFU} / \mathrm{mL}$ ), 2 (moderate, $10-10^{2} \mathrm{CFU} / \mathrm{mL}$ ), 3 (many, $10^{2}-10^{3} \mathrm{CFU} / \mathrm{mL}$ ) and 4 (massive, $>10^{3} \mathrm{CFU} / \mathrm{mL}$ ) ${ }^{23}$.

\section{Candida spp identification}

To identify Candida spp, 100 microliters of oral rinse 10x PBS-diluted were plated on petri dishes with CHROMagar Candida. Later, colonies were plated in tubes with Sabouraud Dextrose Agar (Himedia, India) and incubated at $37^{\circ} \mathrm{C}$ per 24 hours. From such inocula in the exponential growth state, the following were performed: fungal microcultivated test ${ }^{24}$, germ tube formation ${ }^{25}$; hypertonic Sabouraud broth ${ }^{26}$; reduction of trifeniltetrazole chloride; zimogram; API (ID $32 \mathrm{C}$ ); formation of germinate tube, chlamydoconidia production, carbohydrates fermentation and assimilation ${ }^{24}$. The species identification was obtained based on the positivity or negativity of Sandven (1990) tests ${ }^{27}$.

\section{Statistical Analyses}

Statistical analysis was performed using the Graph Pad Prism software (San Diego, CA, USA). Data were not normally distributed. Fisher's exact test and the Chi-squared test were used to compare the number of patients using ART, the number of patients who smoked and the prevalence of different Candida species in the groups. Differences between groups were assessed using Chi-squared test. The Mann-Whitney U test was used to compare two means, and the one-way Kruskal Wallis test was used to compare three or more means. Data are presented as the mean \pm standard deviation, and for the analysis, a confidence interval of $95 \%$ was used, and $p$ values were considered to be significant when they were equal to or less than 0.05 .

\section{RESULTS}

Seventy-three patients participated in this study: 25 who were not HIV-infected and 48 who were HIV-infected. Patients were divided into four groups according to serum status and periodontal condition. Group A: 12 not HIVinfected and periodontally healthy patients; Group B: 13 not HIV-infected and periodontally affected patients; Group C: 19 HIV-infected and periodontally healthy patients; Group D: 29 HIV-infected and periodontally affected patients.

The participants of all groups were homogeneous -regarding epidemiologic and clinical characteristics, as described in Table 1.

Oral Candida spp counting and identification related to HIV-infected and non-infected patients' periodontal conditions

In general, we identified oral Candida spp to have an equivalent distribution in all groups, as described in Table 2.

C. albicans and $C$. parapisilosis were identified in all studied groups. C. tropicalis was identified in the $\mathrm{C}$ and $\mathrm{D}$ groups and C. dubliniensis, and C. glabrata, in the D group exclusively. Although a major Candida spp variety had been verified in the $\mathrm{D}$ group, its prevalence was not statistically significant (Table 2).

Candida spp were distributed in a homogeneous way among groups, but despite this, Candida spp counting was increased in - patients from the D group. Among non-HIVinfected patients, Candida spp counting did not correlate with the periodontal state. In the group A, analysis of the oral rinse revealed that $58.3 \%(n=7)$ of the samples were 
Table 1 - Demographic Data and Clinical Parameters of Subjects Stratified by HIV Status and Oral Condition

\begin{tabular}{|c|c|c|c|c|c|}
\hline & \multicolumn{5}{|c|}{ Group } \\
\hline & A & $\mathrm{B}$ & $\mathrm{C}$ & $\mathrm{D}$ & $P$ value \\
\hline HIV status & Negative & Negative & Positive & Positive & - \\
\hline Oral conditions & Healthy & Gingivitis/Periodontitis & Healthy & Gingivitis/Periodontitis & - \\
\hline Number of subjects & 12 & 13 & 19 & 29 & - \\
\hline Mean age (years) & $35( \pm 9)$ & $37( \pm 9)$ & $38( \pm 9)$ & $39( \pm 5)$ & $0.411^{\mathrm{a}}$ \\
\hline Males (\%) & 50 & 54 & 32 & 55 & $0.4157^{b}$ \\
\hline Smokers (\%) & 8 & 23 & 15 & 34 & $0.2473^{b}$ \\
\hline Mean number of teeth & $27( \pm 4)$ & $27( \pm 5)$ & $27( \pm 5)$ & $26( \pm 5)$ & $0.6106^{a}$ \\
\hline Sites with BOP (\%) & $9( \pm 7)$ & $35( \pm 21)$ & $5( \pm 6)$ & $30( \pm 13)$ & $<0.0001^{a}$ \\
\hline Sites with PPD> $4 \mathrm{~mm}(\%)$ & 0 & $1,2( \pm 2)$ & 0 & $1,3( \pm 2)$ & $<0.0001^{a}$ \\
\hline Use of ART (\%) & & & 84 & 79 & $1.000^{c}$ \\
\hline Mean CD $-4^{+}$cells & & & $514( \pm 312)$ & $387( \pm 276)$ & $0.2254^{d}$ \\
\hline Median viral load (cop/ml) & & & $<50$ & $<50$ & $0.2365^{d}$ \\
\hline
\end{tabular}

aKruskal Wallis test; ${ }^{b}$ Chi-squared test; ${ }^{\circ}$ Fisher's exact test; 'Mann Whitney test. Group A: Not HIV-infected and periodontally healthy patients. Group B: Not HIV-infected and periodontally affected patients. Group C: HIV-infected and periodontally healthy patients. Group D: HIV-infected and periodontally affected patients. BOP: bleeding on probing. PPD: probing pocket depth. ART: Antiretroviral therapy.

Table 2 - Identification of the Oral Candida spp in Studied Groups

\begin{tabular}{lcccccc}
\hline & Group A & Group B & p value & Group C & Group D $^{\mathrm{a}}$ & p value \\
\hline Candida spp & $8(67 \%)$ & $10(77 \%)$ & 0.6728 & $11(58 \%)$ & $24(83 \%)$ & 0.0959 \\
Candida albicans & $7(58 \%)$ & $8(61 \%)$ & 1.000 & $11(58 \%)$ & $23(79 \%)$ & 0.1931 \\
Candida krusei & $0(0 \%)$ & $0(0 \%)$ & - & $0(0 \%)$ & $2(7 \%)$ & 0.5115 \\
Candida parapisilosis & $3(25 \%)$ & $2(15 \%)$ & 0.6447 & $1(5 \%)$ & $2(7 \%)$ & 1.000 \\
Candida tropicalis & $0(0 \%)$ & $0(0 \%)$ & - & $1(5 \%)$ & $2(7 \%)$ & 1.000 \\
Candida dubliniensis & $0(0 \%)$ & $0(0 \%)$ & - & $0(0 \%)$ & $1(3 \%)$ & 1.000 \\
Candida glabrata & $0(0 \%)$ & $0(0 \%)$ & - & $0(0 \%)$ & $3(10 \%)$ & 0.2673 \\
\hline
\end{tabular}

aFisher's exact test. Group A: Not HIV-infected and periodontally healthy patients. Group B: Not HIV-infected and periodontally affected patients. Group C: HIV-infected and periodontally healthy patients. Group D: HIV-infected and periodontally affected patients

Candida carriers, $41.6 \%(\mathrm{n}=5)$ of the patients showed isolated to moderate numbers of $\mathrm{CFU} / \mathrm{mL}$, whereas $16.6 \%$ $(\mathrm{n}=2)$ presented many to massive $\mathrm{CFU} / \mathrm{mL}$. Similar results were found in group B: $63.5 \%(n=8)$ of the samples were Candida carriers; $48.1 \%(\mathrm{n}=6)$ of the patients showed isolated to moderate numbers of $\mathrm{CFU} / \mathrm{mL}$, whereas $15.4 \%$ $(\mathrm{n}=2)$ presented many to massive $\mathrm{CFU} / \mathrm{mL}(\mathrm{p}=0.97)$, as described in Figure 1A. Differently, among HIV-infected patients, group $\mathrm{C}$ presented $36.8 \%(\mathrm{n}=7)$ of the samples with isolated to moderate numbers of $\mathrm{CFU} / \mathrm{mL}$ and $21.1 \%$ $(\mathrm{n}=4)$ showed many to massive $\mathrm{CFU} / \mathrm{mL}$. High $\mathrm{CFU} / \mathrm{mL}$ was noted in the group D, 27.6\% $(\mathrm{n}=8)$ and $55.2 \%(\mathrm{n}=16)$ showed isolated to moderate, and many to massive numbers of $\mathrm{CFU} / \mathrm{mL}$, respectively ( $\mathrm{p}=0.04$ ), as described in Figure 1B.
It is important to note that Candida spp counting was similar between non-HIV-infected and infected patients who were periodontally healthy, groups $\mathrm{A}$ and $\mathrm{C}(\mathrm{p}=0.94)$.

Influence of viral load and CD4+L count on the Candida spp carriage of HIV-infected patients

Among HIV-infected patients, we verified that Candida spp carriage was associated with viral load and CD4+L count. The 11 patients who presented less than $200 \mathrm{cells} / \mathrm{mm}^{3}$ CD4+L presented $9 \%(\mathrm{n}=1)$ with none CFU count; $9 \%$ $(\mathrm{n}=1)$ and $82 \%(\mathrm{n}=9)$ showed isolated to moderate and many to massive numbers of $\mathrm{CFU}$, respectively. The 20 patients who presented between 200 and $500 \mathrm{CD} 4+\mathrm{L} / \mathrm{mm}^{3}$ presented $30 \%(\mathrm{n}=6)$ with none $\mathrm{CFU}$ count, $30 \%$ presented isolated to 
(A)

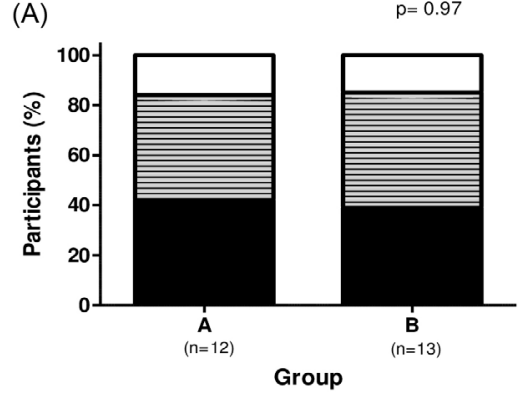

(B)

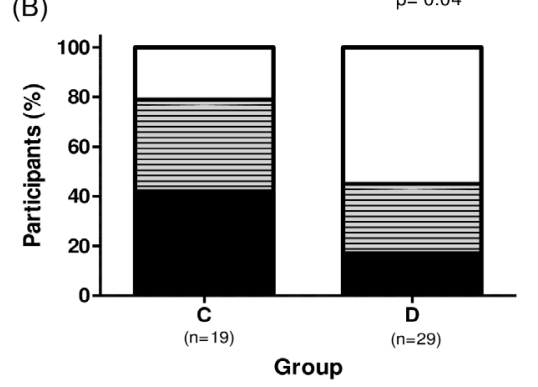

Figure 1 - (A) Relative Candida spp carriage in oral rinses of non-HIV-infected patients without (Group A) and with (Group B) periodontal diseases; $p=0.97$, Chi-squared test; (B) Relative Candida spp carriage in HIV-infected patients without (Group C) and with (Group D) periodontal diseases; $p=0.04$, Chisquared test.

moderate CFU count and $40 \%(n=8)$ showed many to massive CFU count. Candida spp carriage was reduced in the 17 patients with more than $500 \mathrm{CD} 4+\mathrm{T} / \mathrm{mm}^{3}$, when compared to the patients who presented less than 200 cells $/ \mathrm{mm}^{3}$, $35.3 \%(n=6)$ presented none CFU count, 47\% $(n=8)$ and $17.7 \%(n=3)$ showed isolated to moderate and many to massive numbers of CFU, respectively $(\mathrm{p}=0,003)$, as demonstrated in Figure 2A.

No association between viral load and Candida spp carriage was detected. Thirty-three patients with viral load less than 100 copies $/ \mathrm{mL}$ presented $27 \%(\mathrm{n}=9)$ no CFU count, $36.5 \%(n=12)$ with isolated to moderate and $36.5 \%$ with many to massive CFU/ mL commensal Candida spp, while 15 patients presented a viral load greater than 100 copies $/ \mathrm{mL}$ showed $26.7 \%(n=4)$ of the participants with none CFU/mL count, $20 \%(\mathrm{n}=3)$ and $53.3 \%(\mathrm{n}=8)$ with isolated to moderate and many to massive numbers of $\mathrm{CFU} / \mathrm{mL}$, respectively $(\mathrm{p}=0.45)$, as demonstrated in Figure $2 \mathrm{~B}$.

\section{DISCUSSION}

The majority of HIV-infected patients develops Candida spp-associated clinical lesions. These lesions can increase in frequency and severity according to the progression of HIV infection ${ }^{11}$. Although the clinical manifestations of candidiasis depend on mucosal fungus adhesion and colonization $^{28}$, the asymptomatic Candida spp in HIV-
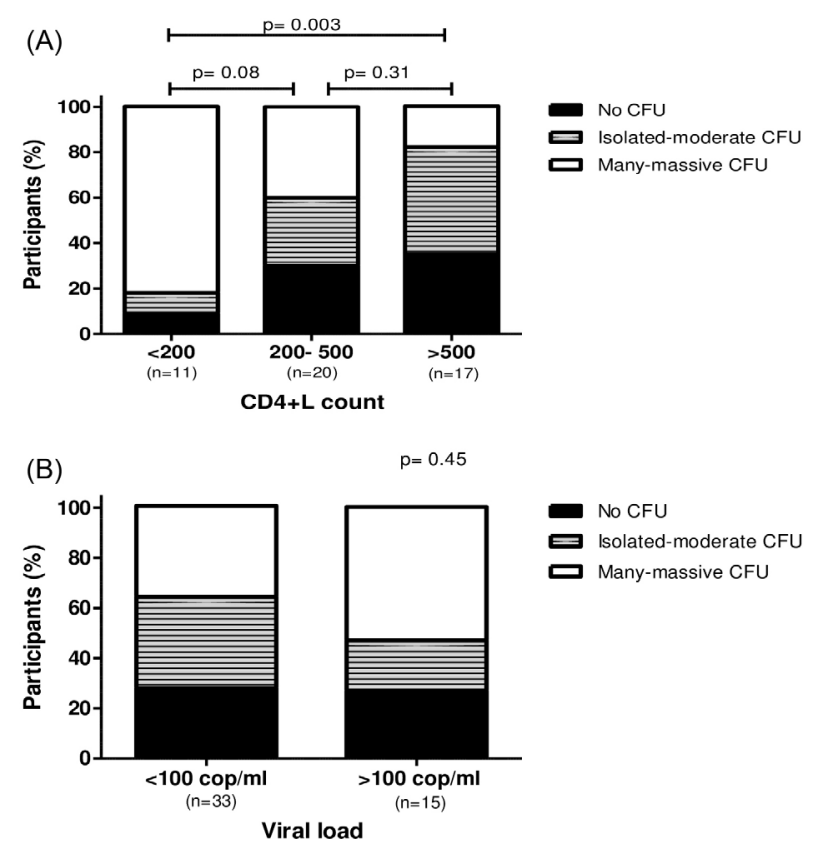

Figure 2 - (A) Relative Candida spp carriage in HIV-infected patients with different CD4+T cells count $(<200,200-500$ and $>500$ cells $/ \mathrm{mm}^{3}$ ). A significant difference was found between patients with less than $200 \mathrm{CD} 4+\mathrm{T}$ cells/ $\mathrm{mm} 3$ and patients with more than $500 \mathrm{CD} 4+\mathrm{T}$ cells $/ \mathrm{mm}^{3} ; \mathrm{p}=0.003$, Chi-squared test; (B) Relative Candida spp carriage in HIV-infected patients with different viral loads ( $<100$ and $>100$ copies $/ \mathrm{mL}$ ); $p=0.45$, Chi-squared test.

infected patients with low CD4+L count is also associated with clinical disease ${ }^{29}$. This is the reason why it is of great importance to know the predisposing factors of increased prevalence of commensal Candida spp in the oral cavity, especially HIV-positive patients.

In this study, we found similar prevalences of different commensal Candida species in the oral rinse from nonHIV-infected and infected patients, regardless of their periodontal state.

The prevalence found in our study was higher than that in other studies. Kamtane et al..$^{30}$, in 2003 , verified salivary Candida spp in $15 \%$ of non-HIV-infected patients and $55 \%$ in HIV-infected patients. Other studies reported fungus colonization in HIV-positive patients between $44 \%$ and $62 \%{ }^{9,31-33}$. In the present study, we verified the presence of different Candida spp in $72 \%$ of non-HIV-infected patients and $73 \%$ of HIV-infected patients. The variation among the different studies may be due the collection methodology, such as the use of swabs, total saliva collection and oral rinse. According to Samaranayake et $a .^{22}$, oral rinse is the most sensitive technique for quantifying and detecting Candida spp, as used in the present study. No differences in Candida spp prevalences were detected in these study groups.

Candida spp carriage was increased in patients with less than 200 CD4+L cells when compared to patients presenting 
more than 500 cells $/ \mathrm{mm}^{3}(\mathrm{p}=0.003)$. These results agree with previous studies that verified more colonization in inferior $\mathrm{CD} 4+\mathrm{L}$ counting, 200 cells $/ \mathrm{mm}^{333-35}$. On the other hand, some studies have not found this association ${ }^{32-36}$.

The highlight of our work is the high commensal Candida spp count in HIV-infected and periodontally affected patients, when compared to HIV-infected patients not affected by periodontal disease. These results address the importance of oral health in oral candidiasis prevention because Candida spp density is associated with a higher risk for candidiasis development ${ }^{29}$. On the other hand, periodontal conditions were not observed as an important factor for Candida spp carriage in non-HIV-infected patients. Non-HIV-infected patients presented similar Candida spp prevalence and counting, regardless of the periodontal state, and these results agree with those of Darwazeh et al. ${ }^{37}$, who verified a similar prevalence and counting in 149 orally healthy patients. One limitation of this study was the absence of the sample size calculation, therefore, the study may not have enough power to detect the difference between groups.

Among HIV-infected patients, the periodontal state did not influence Candida spp presence or absence, but it was responsible for the 4.8 fold increase in counting. This increase is epidemiologically important as demonstrated by Fong et al..$^{29}$, in 1997, who showed that candidiasis only developed in patients with persistent asymptomatic carriage of C. albicans.

The predisposal of HIV-infected patients to more oral C. albicans carriage, associated with the influence of oral hygiene on Candida spp carriage, are responsible for the high values of Candida spp in HIV-infected patients who have periodontal disease, as shown in this present study. It is important to emphasize that HIV-infected patients who presented good periodontal conditions had Candida spp levels similar to those of non-HIV-infected patients, renforcing the affirmation that the periodontal condition may be considered a factor -of increases in the count of Candida spp in HIV-infected patients.

Many studies have shown $C$. albicans to be an etiologic and worsening factor of periodontal disease $\mathrm{e}^{19,20,38}$. This study shows that periodontal disease increases with Candida spp carriage, acting as a vicious cycle in HIV-infected patients because in this condition, periodontal disease increases Candida spp counts, which worsen periodontal conditions.

In conclusion, periodontal disease may be a factor responsible for the increase in commensal Candida spp count in HIV-infected patients, and based on current medical literature, it is reasonable to affirm that this increase may predispose the patient to the development of the clinical manifestations of candidiasis.

\section{CONFLICT OF INTERESTS}

The authors confirm that this article content has no conflict of interests.

\section{ACKNOWLEDGEMENTS}

The authors thank Prof. L.P. Samaranayake for the discussions about the design of the study. This work was supported by funds from the National Counsel of Technological and Scientific Development (CNPq), Process $\mathrm{N}^{\mathrm{o}} 477754 / 2009-0$, and the Coordination of Improvement of Higher Level Personnel (CAPES).

\section{REFERENCES}

1. Eggimann P, Garbino J, Pittet D. Epidemiology of Candida species infections in critically ill non-immunossupressed patients. Lancet Infect Dis. 2003;3:685-702.

2. Li YY, Chen WY, Li X, Li HB, Li HQ, Wang L, et al. Asymptomatic oral yeast carriage and antifungal susceptibility profile of HIV-infected patients in Kunming, Yunnan Province of China. BMC Infect Dis. 2013;13:46.

3. Lockhart SR, Joly S, Vargas K, Swails-Wenger J, Enger L, Sool DR. Natural defenses against Candida colonization breakdown in the oral cavities of the elderly. J Dent Res. 1999;78:857-68.

4. Vargas KG, Joly S. Carriage frequency, intensity of carriage, and strains of oral yeast species vary in the progression to oral candidiasis in human immunodeficiency virus-positive individuals. J Clin Microbiol. 2002;40:341-50.

5. Fidel PL Jr. Candida-host interactions in HIV disease: relationships in oropharyngeal candidiasis. Adv Dent Res. 2006;19:80-4.

6. Ramos-Gomez FJ, Flaitz C, Catapano F, Murray P, Milnes AR, Dorenbaum A. Classification, diagnostic criteria, and treatment recommendations for orofacial manifestations in HIV-infected pediatric patients. Collaborative Workgroup on Oral Manifestations of Pediatric HIV Infection. J Clin Pediatr Dent. 1999;23:85-96.

7. Scully C, el-Kabir M, Samaranayke LP. Candida and oral candidosis: a review. Crit Rev Oral Biol Med. 1994;5:125-57.

8. Samaranayake L. Commensal oral Candida in Asian cohorts. Int J Oral Sci. 2009;1:2-5.

9. Costa CR, Cohen AJ, Fernandes OF, Miranda KC, Passos XS, Souza LK, et al. Asymptomatic oral carriage of Candida species in HIV-infected patients in the highly active antiretroviral therapy era. Rev Inst Med Trop São Paulo. 2006;48:257-61.

10. Felix DH, Wray D. The prevalence of oral candidiasis in HIVinfected individuals and dental attenders in Edinburgh. J Oral Pathol Med. 1993;22:418-20. 
11. Lourenço AG, Figueiredo LT. Oral lesions in HIV infected individuals from Ribeirão Preto, Brazil. Med Oral Patol Oral Cir Bucal. 2008;13:E281-6.

12. Lourenço AG, Motta AC, Figueiredo LT, Machado AA, Komesu MC. Oral lesions associated with HIV infection before and during the antiretroviral therapy era in Ribeirão Preto, Brazil. J Oral Sci. 2011;53:379-85.

13. de Repentigny L, Lewandowski D, Jolicoeur P. Immunopathogenesis of oropharyngeal candidiasis in human immunodeficiency virus infection. Clin Microbiol Rev. 2004;17:729-59.

14. Soysa NS, Ellepola AN. The impact of cigarette/tobacco smoking on oral candidosis: an overview. Oral Dis. 2005;11:268-73.

15. Kleinegger CL, Lockhart SR, Vargas K, Soll DR. Frequency, intensity, species, and strains of oral Candida vary as a function of host age. J Clin Microbiol. 1996; 34:2246-54.

16. Starr JR, White TC, Leroux BG, Luis HS, Bernardo M, Leitao J, et al. Persistence of oral Candida albicans carriage in healthy Portuguese schoolchildren followed for 3 years. Oral Microbiol Immunol. 2002;17:304-10.

17. Nikawa H, Hamada T, Yamamoto T. Denture plaque-past and recent concerns. J Dent. 1998;26:299-304.

18. Hannula J, Dogan B, Slots J, Okte E, Asikainen S. Subgingival strains of Candida albicans in relation to geographical origin and occurrence of periodontal pathogenic bacteria. Oral Microbiol Immunol. 2001;16:113-8.

19. Järvensivu A, Hietanen J, Rautemaa R, Sorsa T, Richardson M. Candida yeasts in chronic periodontitis tissues and subgingival microbial biofilms in vivo. Oral Dis. 2004;10:106-12.

20. Canabarro A, Valle C, Farias MR, Santos FB, Lazera M, Wanke B. Association of subgingival colonization of Candida albicans and other yeasts with severity of chronic periodontitis. J Periodontal Res. 2013;48:428-32.

21. Ramseier CA, Kinney JS, Herr AE, Sugai JV, Shelburne CA, Rayburn LA, et al. Identification of pathogen and host-response markers correlated with periodontal disease. J Periodontol. 2009;80:436-46.

22. Samaranayake LP, MacFarlane TW, Lamey PJ, Ferguson MM. A comparison of oral rinse and imprint sampling techniques for the detection of yeast, coliform and Staphylococcus aureus carriage in the oral cavity. J Oral Pathol. 1986;15:386-88.

23. Klaus K, Eichenauer J, Sprenger R, Ruf S. Oral microbiota carriage in patients with multibracket appliance in relation to the quality of oral hygiene. Head Face Med. 2016;12:28.

24. Lacaz CS, Porto E, Martins JE. Micologia médica: fungos actinomicetos e algas de interesse médico. $8^{\mathrm{a}}$ ed. São Paulo: Sarvier; 1991.

25. Sindrin JJ, Rocha MF. Micologia médica à luz dos autores contemporâneos. Rio de Janeiro: Guanabara Koogan; 2004.

26. Alves SH, Milan EP, de Laet Sant'Ana P, Oliveira LO, Santurio
JM, Colombo AL. Hypertonic sabouraud broth as a simple and powerful test for Candida dubliniensis screening. Diagn Microbiol Infect Dis. 2002;43:85-6.

27. Sandven P. Laboratory identification and sensitivity testing of yeast isolates. Acta Odontol Scand. 1990;48:27-36.

28. Hisajima T, Ishibashi H, Yamada T, Nishiyama Y, Yamaguchi, Funakoshi K, et al. Invasion process of Candida albicans to tongue surface in early stages of experimental murine oral candidiasis. Med Mycol. 2008;46:697-704.

29. Fong IW, Laurel M, Burford-Mason A. Asymptomatic oral carriage of Candida albicans in patients with HIV infection. Clin Invest Med. 1997;20:85-93.

30. Kamtane S, Subramaniam A, Survarna P. A comparative study of oral candidal carriage and its association with CD4 count between HIV-positive and healthy individuals. J Int Assoc Provid AIDS Care. 2013;12:39-43.

31. Hung CC, Yang YL, Lauderdale TL, McDonald LC, Hsiao CF, Cheng $\mathrm{HH}$, et al. Colonization of human immunodeficiency virus-infected outpatients in Taiwan with Candida species. J Clin Microbiol. 2005;43:1600-3.

32. Campisi G, Pizzo G, Milici ME, Mancuso S, Margiotta V. Candidal carriage in the oral cavity of human immunodeficiency virus infected subjects. Oral Surg Oral Med Oral Pathol Oral Radiol Endod. 2002;93:281-6.

33. Delgado AC, de Jesus Pedro R, Aoki FH, Resende MR, Trabasso P, Colombo AL, et al. Clinical and microbiological assessment of patients with a long-term diagnosis of human immunodeficiency virus infection and Candida oral colonization. Clin Microbiol Infect. 2009;15:364-71.

34. Lin JN, Lin CC, Lai CH, Yang YL, Chen HT, Weng HC, et al. Predisposing factors for oropharyngeal colonization of yeasts in human immunodeficiency virus-infected patients: a prospective cross-sectional study. J Microbiol Immunol Infect. 2013;46:129-35.

35. Sangeorzan JA, Bradley SF, He X, Zarins LT, Ridenour GL, Tiballi $\mathrm{RN}$, et al. Epidemiology of oral candidiasis in HIVinfected patients: colonization, infection, treatment, and emergence of fluconazole resistance. Am J Med. 1994;97:339-46.

36. Gottfredson M, Cox GM, Indridason OS, Almeida GM, Heald AE, Perfect JR. Association of plasma levels of human immunodeficiency virus type 1 RNA and oropharyngeal Candida colonization. J Infect Dis. 1999;180:534-7.

37. Darwazeh AM, Hammad MM, Al-Jamaei AA.The relationship between oral hygiene and oral colonization with Candida species in healthy adult subjects. Int J Dent Hyg. 2010;8:12833.

38. Odden K, Schenck K, Kooppang H, Hurlen B. Candidal infection of the gingiva in HIV-infected persons. J Oral Pathol Med. 1994;23:178-83. 